\title{
Editorial
}

Cerebrovascular Diseases
Cerebrovasc Dis 2018;45:I-II

DOI: $10.1159 / 000489054$

Published online: April 26, 2018

\section{Synergistic Strategies to Promote Stroke Research}

Randomized controlled trials (RCTs) have convincingly confirmed the benefit of multiple strategies to treat and/or prevent stroke: endovascular mechanical thrombectomy has been powered by the simultaneous publication of several similarly designed RCTs in a very short time [1] when compared to more than a decade of heterogeneous studies requested to demonstrate that intravenous thrombolysis was beneficial in patients with acute ischemic stroke up to $4.5-6 \mathrm{~h}$ after onset of symptoms. This period is still ongoing, and we await the results of the MRI-Guided Thrombolysis Study for Stroke with Unknown Time of Onset to be published very soon. The debate about a benefit or risks of transcatheter closure of patent foramen ovale versus medical therapy after cryptogenic stroke lasted for a longer time: despite initial supportive results from 3 long-lasting studies published last year, we still continue to miss meaningful clinical results even after the presentation of the first meta-analysis published in this issue of Cerebrovascular Disease by Darmoch et al. [2] from the USA.

This is due to the very different design and analysis parameters of these studies as expressed by the high heterogeneity factors.
The editorial written by the highly prominent senior of stroke research L.R. Caplan from Boston, USA, nicely illustrates by example of Atrial Fibrillation and Stroke the erroneous and long-lasting ways to which clinical research might have to go sometimes [3].

Today, joint methodologies may provide useful results once applied to quite different questions: early prediction of the effect of revascularization on ischemic cerebral edema as submitted by Bevers et al. [4] from the USA and a neuropathological MRI study on cerebral amyloid angiopathy (CAA) in postmortem tissue by Guidoux et al. [5] from France. Bevers et al. [4] reaffirm the association of ADCr with outcome after stroke and support the idea that reperfusion may attenuate rather than enhance poststroke edema, which indicates that the degree of edema with and without revascularization may be predicted by ADCr. Guidoux et al. [5] confirm that both hypertension and CAA frequently coexist in patients with intracerebral hemorrhage (ICH); however, MRI-detected microbleeds, as proven by histological analysis, were twice as common in patients with CAA as in those with hypertensive $\mathrm{ICH}$.

This journal is dedicated to translational studies with high emphasis on clinically relevant problems and this is 
well illustrated by 3 more studies to be mentioned in this editorial, making this issue one of the best ever published: Chen et al. [6] from China show that fisetin effectively alleviates ICH by downregulating proinflammatory cytokines and attenuating nuclear factor-kappa B signaling. Their data suggest fisetin as a valuable natural flavonol for clinical management of ICH-induced brain injury. Suzuki et al. [7] from Japan provide further evidence that aspirin prevents aneurysm rupture in a mouse intracranial aneurysm model, while cilostazol did not. Aspirin, the most fre- quently used drug for patients with ischemic myocardial and cerebral diseases, may also be effective in preventing cerebral aneurysmal rupture. This concept is currently investigated in a large European RCT. And finally, Mortensen et al. [8] from Denmark for the first time show that the presence of the high expression serotonin transporter genotype $\left(\mathrm{L}_{\mathrm{A}} \mathrm{L}_{\mathrm{A}}\right)$ may be associated with a lower risk of ischemic stroke/transient ischemic attack and suggest that this concept needs further elaboration in clinical studies.

M.G. Hennerici, Mannheim

\section{References}

1 Goyal M, Menon BK, van Zwam WH, Dippel DW, Mitchell PJ, Demchuk AM, et al: Endovascular thrombectomy after large-vessel ischaemic stroke: a meta-analysis of individual patient data from five randomised trials. Lancet 2016;387:1723-1731.

2 Darmoch F, Al-Khadra Y, Soud M, Fanari Z, Alraies MC: Transcatheter closure of patent foramen ovale versus medical therapy after cryptogenic stroke: a meta-analysis of randomized controlled trials. Cerebrovasc Dis 2018;45:162-169.

-3 Caplan LR: Atrial fibrillation, past and future: from a stroke non-entity to an over-targeted cause. Cerebrovasc Dis 2018;45:149-153.
Bevers MB, Battey TWK, Ostwaldt AC, Jahan R, Saver JL, Kimberly WT, Kidwell CS: Apparent diffusion coefficient signal intensity ratio predicts the effect of revascularization on ischemic cerebral edema. Cerebrovasc Dis 2018;45:93-100.

Guidoux C, Hauw JJ, Klein IF, Labreuche J, Berr C, Duyckaerts C, Amarenco P: Amyloid angiopathy in brain hemorrhage: a postmortem neuropathological-magnetic resonance imaging study. Cerebrovasc Dis 2018;45:124131.
Chen C, Yao L, Cui J, Liu B: Fisetin protects against intracerebral hemorrhage-induced neuroinflammation in aged mice. Cerebrovasc Dis 2018;45:154-161.

Suzuki T, Kamio Y, Makino H, Hokamura K, Kimura T, Yamasaki T, Hiramatsu $\mathrm{H}$, Umemura K, Namba H: Prevention effect of antiplatelets on aneurysm rupture in a mouse intracranial aneurysm model. Cerebrovasc Dis 2018;45:180-186.

Mortensen JK, Kraglund KL, Johnsen SP, Mors O, Andersen G, Buttenschøn HN: The serotonin transporter gene polymorphisms and risk of ischemic stroke. Cerebrovasc Dis 2018;45:187-192. 